\title{
FAKE NEWS NO SENTIDO EXTRA-MORAL, OU SOBRE A REALIDADE MATERIAL DAS PALAVRAS
}

\author{
Rafael Alonso ${ }^{\mathrm{a}}$
}

\begin{abstract}
RESUMO:
O presente ensaio assume o pressuposto de que a realidade estrutura-se linguisticamente. Com base nessa ideia, a proposta é refletir sobre uma forma política e imaginativa de pensamento que faça do aspecto aparentemente não objetivo da realidade uma oportunidade para retomar o contato com a materialidade sensível das coisas e com a efetividade das palavras. Isso implica pensar as fake news fora da dicotomia verdade e mentira.
\end{abstract}

PALAVRAS-CHAVE: realidade; língua; fake news.

Recebido em: 31/05/19

Aprovado em: 11/10/19

$\mathrm{N}$ o clássico "A obra de arte na era de sua reprodutibilidade técnica", de 1936, Walter Benjamin assinala que "a crise da democracia pode ser interpretada como uma crise nas condiçôes de exposição do político profissional" (BENJAMIN, 1994, p. 183). O filósofo identifica que o estabelecimento definitivo do cinema e do rádio atrofiou o parlamento e os espaços públicos de troca simbólica. Assim, o político não mais representaria diante de um público, mas frente a um aparelho. Da mesma forma, o ator profissional, até então entendido como ator de teatro, não mais encenaria para um público, mas diante da câmera. Os resultados da performance do político e do ator não

a Doutor em Literatura pela Universidade Federal de Santa Catarina (UFSC). Porfessor dos cursos de Comunicação, Cinema e Design da Unisociesc, em Joinville-SC. Email. rafamalonso@gmail.com 
seriam mais medidos pela reação imediata do público ouvinte, mas estariam submetidos ao crivo dos testes maquinais dos aparelhos (gravação, edição, efeitos especiais etc.). A política em sentido tradicional, enquanto permutação de bens e ideias no espaço público, caminharia para se converter em publicidade, com a consequente transformação da massa em audiência.

Em linhas gerais, os movimentos de força da arte e da política transferiram-se para a imagem. A ação política no mundo estaria ligada a um jogo crítico com a técnica, afinal, não seriam apenas o ator e o político profissionais que passariam a representar para o aparelho. Todos os cidadãos, e melhor seria dizer, modernamente, todos os funcionários, também precisariam defender a sua dignidade diariamente frente aos aparelhos, em seus postos de trabalho.

Em meio a essa ebulição, Benjamin (1994) busca articular um novo conceito de arte e de política que não fossem apropriáveis pelo fascismo. A preocupação do filósofo alemão voltava-se para a capacidade do regime nazista de permitir que as massas expressassem as suas emoçóes, vendo-se na tela, preservando intactas, no entanto, as relaçóes sociais de poder e propriedade. Com Hitler, a massa ainda estava na rua, nos estádios e nos desfiles, mas já estava também nas telas do cinema. O fascismo, como lembra Susan Buck-Morss (1996), não cria a autoalienação sensorial, mas a manipula habilmente de acordo com os seus fins. Nesse sentido, a propaganda nazista capta e explora o regozijo da massa, em certo sentido legítimo, conforme Benjamin (1994), em ver-se projetada na tela.

O regime autoritário opera em movimento duplo. De uma parte, permite às massas que extrapolem, nas telas, as suas necessidades pulsionais. De outra, com a transformação do ditador em programa reprodutível de computador, faz parecer que seu poder, sustentado em última instância pela violência extrema, se ampara numa lógica horizontal de identificação, como se o fuhrer fosse uma "pessoa comum" 1 .

Com base nessas premissas, a proposta deste ensaio é inserir as fake news no contexto de dois movimentos que estão interligados: o esvaziamento do espaço público enquanto locus de trocas simbólicas e o esgotamento da noção

1 SLOTERDIJK, Peter. O desprezo das massas: ensaio sobre lutas culturais na sociedade moderna. Trad. Claudia Cavalcanti. São Paulo: Estação Liberdade, 2016. 
tradicional de política como manifestação discursiva e presencial de ideias. As fake news, aqui, são tomadas como formas discursivas (textos ou imagens) desincumbidas da necessidade de corresponder a alguma realidade material, provenha esta da vida corrente ou da própria língua. A presente reflexão pretende mostrar que as fake news, menos do que abandonar a ideia do fato, do factual, deixam de lado a potência material e significativa da língua.

Se pensamos nas eleições e, mais precisamente, no exemplo brasileiro, pode-se concluir que os governantes são escolhidos com base em uma perspectiva narrativa e, portanto, ficcional. Não parece haver, desse modo, uma relação evidente que una a opção por um determinado candidato a uma consequente melhora, ao menos desejada, na vida prática do sujeito votante. Escolhe-se um candidato em razão de uma identificação quase pessoal, ainda que essa pessoalidade se estabeleça em programas eleitorais, lives, tuítes, montagens etc. Mesmo os planos de governo, costumeiramente conhecidos como documentos que apresentam ideias vagas e abrangentes, resumem-se agora a um conjunto de bravatas, bordóes e convocaçóes duvidosamente patrióticas e religiosas.

Desse modo, a tese central deste trabalho é a de que as fake news, como fenômeno contemporâneo disseminado nas redes sociais, indicam, para além da distinção entre verdade e mentira, uma crise na capacidade significativa das palavras. Combatê-las não demandaria, assim, opor o verdadeiro ao falso, mas religar as palavras a uma materialidade sensível. Isso deve implicar na retomada ética da responsabilidade, entendendo esta última como a exigência do sujeito discursivo em responder pelas suas ações, como também, e principalmente, pelas suas palavras.

O filósofo tcheco, naturalizado brasileiro, Vilém Flusser, que, em fuga do regime nazista, chega ao Brasil em 1940, e por aqui vive pouco mais de três décadas, publica o seu primeiro livro, Lingua e Realidade, em 1963. A hipótese principal de Flusser é que a nossa realidade, ou aquilo que entendemos genericamente como "mundo concreto", estrutura-se por meio da língua que elegemos para articulá-la. A realidade não se apresenta como algo "em si”, essencial, descritível. Conhecê-la, em termos epistemológicos, não seria adequar o sujeito pensante e o objeto estático. Conhecer a realidade seria, segundo Flusser (2007), articular linguisticamente o "dado bruto" que acedia 
os sentidos (FLUSSER, 2007, p. 19).

Esse mesmo aspecto marcaria o potencial político do migrante plurilíngue, como é o caso de Flusser, já que tantas podem ser as realidades quantas forem as línguas articuláveis. Aquele que se articula em múltiplas línguas reconhece que não há uma única e definitiva realidade. O próprio filósofo fez da autotradução um método de trabalho. Ele escreveu em quatro línguas - inglês, francês, alemão e português - e, deliberadamente, evitou a língua materna, o tcheco. As várias versóes de seus textos não se compuseram de acréscimos ou subtraçóes, mas de conversóes para outros idiomas. Traduzir é, para o autor, criar pontes por sobre o abismo do inarticulável. É viver bodenlos ${ }^{2}$, do alemão, sem fundamento ou sem chão, experiência intelectual que correspondia perfeitamente à sua experiência existencial. Se aquele que domina múltiplas línguas costuma se definir como apátrida, não raro governos fascistas fizeram, e fazem, da língua materna um dos pilares do nacionalismo. O estrangeiro, como aponta Jacques Derrida (2003), não é justamente aquele que vem de "fora" e não fala a nossa língua ?

Flusser (2007) não nega a existência de uma realidade objetiva, mas a insere dentro do conjunto das palavras em estado nascente. A realidade estaria composta, assim, pelas palavras já articuladas e pelas palavras em potencial. As segundas estariam incluídas no que o filósofo chama de "dado bruto" ou "elemento concreto". Flusser (2007) não recusa uma realidade que tocaria inicialmente o nosso sistema sensorial e que, na maioria das ocasióes, se limita a uma impressão fugaz ou a uma sensação efêmera, mas ressalta que a realidade, para fazer sentido ao sujeito vivente, precisa ser convertida em língua. Essa seria a verdadeira tarefa do poeta que, deslocado ao limiar onde nascem as palavras, esgarça os limites da língua e flerta com o indizível a fim de lançar novas palavras na conversação infinita. Nas palavras de Flusser (2007), cabe ao

2 Bodenlos: uma autobiografia filosófica, é o título da autobiografia de Flusser, redigida quando do retorno à Europa, no começo da década de 1970. Já a biografia de Flusser, publicada em 2017 por Gustavo Bernardo e Rainer Guldin, também recebeu o título O homem sem chão: a biografia de Vilém Flusser. Referências completas ao final.

3 Ver, a esse respeito: DERRIDA, Jacques. Anne Dufourmantelle convida Jaques Derrida a falar Da hospitalidade/Jacques Derrida [Entrevistado]. Trad. Antônio Romane. São Paulo: Escuta, 2003. 
poeta criar versos para serem conversados.

Quase um século antes, em 1873, Friedrich Nietzsche publica um ensaio, hoje bastante conhecido, de título "Sobre verdade e mentira no sentido extra-moral", para defender que a "coisa em si" ou a essência material das coisas é inapreensível e não captável. Ele separa o que é da ordem das coisas daquilo que é da ordem das designações. Nesse sentido, nós não possuiríamos as coisas mesmas, mas metáforas, por mais estreita que seja a relação entre a posse das coisas e a sua nomeação (NIETZSCHE, 2009, p. 532).

Segundo Nietzsche (2009), todo conceito nasce da "igualação do não-igual”, e, em abono ao seu argumento, cita dois exemplos díspares, o das folhas e o da ideia de honestidade, mas que permitem aclarar a amplitude de uma realidade que depende de uma longa cadeia metafórica para fazer sentido (NIETZSCHE, 2009, p. 534). Não deixa de ser curiosa a escolha do filósofo pelo termo honestidade para exemplificar o funcionamento abstrato das construçóes conceituais. Esse mesmo termo é recorrentemente empregado, hoje em dia, na definição do que deve ser o primeiro critério na escolha de um político.

Se as palavras, portanto, estão carregadas de um elemento abstrato, consequentemente, a noção de verdade, que pressupóe uma ligação sem resto entre coisa e palavra, deve ser colocada em xeque. Em igual modo, se as palavras não traduzem as coisas mesmas, mas as representam, ou as substituem, supor que um sujeito de discurso fala a verdade equivale a afirmar que as suas palavras coincidem com a realidade, entendimento que conduziria a uma contradição sem solução. A conclusão de Nietzsche (2009) é que a verdade não se sustenta fora do âmbito moral. Não é sem razão, também, que as fake news dificilmente operam fora do regime da verdade. As palavras que compóem essa $s$ narrativas não se prestam mais à significação, mas, como conceitos fechados, servem de pretexto para reforçar uma crença já estabelecida.

Talvez sem a mesma radicalidade, Ferdinand de Saussure, no Curso de Linguistica Geral, ministrado entre 1907 e 1910 e publicado postumamente, em 1916, graças ao esforço de alguns dos poucos alunos que o frequentaram, asseverou que o signo linguístico, por meio do qual tomamos contato com a realidade, se define pela sua arbitrariedade. No exemplo dado pelo autor, não existe razão lógica que una o mar, com sua imensidão e profundidade sem limite, à palavra monossilábica e de três letras m-a-r: "O signo linguístico não une uma coisa e 
uma palavra, mas um conceito e uma imagem acústica” (SAUSSURE, 2006, p. 80). Com base nessa premissa, a imagem acústica ocupa o papel do significante, e o conceito (e não o mundo concreto) assume o posto do significado.

Para Saussure (2006), esse meio de expressão arbitrário passaria a ter validade em função de hábitos coletivos de utilização e de acordos convencionalizados. $\mathrm{O}$ valor linguístico da significação residiria no consenso, ou seja, menos na relação com as coisas do que na relação com outras palavras. Valores, para Saussure (2006), são distintivos, uma vez que não se definem positivamente pelo seu conteúdo, mas negativamente em relação aos outros termos do mesmo sistema. Os fonemas, por exemplo, são, em sua concepção, entidades opositivas, relativas e negativas.

Curiosamente, é o aspecto arbitrário do signo linguístico que faz da língua um sistema, ao mesmo tempo, imodificável e mutável. Por um lado, o falante recebe a língua como um produto acabado, resultado de um longo processo histórico que ele é incapaz de recompor, o que confere um aspecto imotivado às suas escolhas. Assim, se crescemos com a ideia de que o suporte sobre o qual comemos ou apoiamos nossos computadores recebe o nome de mesa, não poderemos, arbitrariamente, chamá-lo de árvore, sob o risco de não sermos compreendidos. Por outro lado, é também a arbitrariedade que nos permite estabelecer não importa que relação entre a matéria fônica e as ideias. Para Saussure (2006), a língua é um patrimônio herdado que quase não nos dá margem de manobra, ao mesmo tempo que se modifica, com o tempo, por meio de mecanismos não conhecidos pelos falantes. A mutabilidade, o deslocamento na relação entre o significante e o significado, que define o trabalho poético com a língua, é deixada em segundo plano por Saussure.

Para a presente argumentação, todavia, cumpre notar que Saussure (2006) localiza na língua o domínio da articulação. Os sons e os pensamentos são massas amorfas que vagam em regiôes não localizáveis à procura de pontos de intersecção de sentido. Saussure (2006) reforça, ainda, que a linguística trabalha no terreno limítrofe onde os elementos se combinam, sendo que "esta combinação produz uma forma, não uma substância” (SAUSSURE, 2006, p. $131)^{4}$. Ainda que com diferenças, também há, no filósofo de Genebra, o pos-

4 Mais tarde, o dinamarquês Louis Hjelmslev formalizou os conceitos de forma e substância em relação aos processos linguísticos. Ver, por exemplo: HJELMSLEV, Louis. Prolegômenos a uma teoria da linguagem. São Paulo: Perspectiva, 2006. Obra publicada originalmente em 1943. 
tulado do caráter linguístico da realidade.

Em 1965, Roland Barthes publica Elementos da Semiologia, talvez a primeira tentativa sistemática de transpor a linguística de Saussure para o terreno de outra ciência, a recém-inaugurada Semiótica ou Semiologia. Fusão das palavras gregas semeion, sinal, e logos, estudo, esse campo de saber se abre no contexto de profusão das imagens: cinema, televisão, revistas ilustradas, outdoors, painéis eletrônicos etc. Em termos semióticos, observava-se um aumento exponencial das chamadas "linguagens não-verbais", o que impunha à crítica, até então apoiada em pressupostos literários, que partisse em busca de novas categorias analíticas, as quais pudessem transcender o objeto linguístico.

A escolha de Barthes (2006), porém, não corrobora inteiramente esse veredicto. Ele sugere inverter a proposição do próprio Saussure, para o qual a Linguística se constituía de um segmento, mesmo que privilegiado, no quadro da Ciência Geral dos Signos. Sua opção é por da Semiologia, esta ciência supostamente mais abrangente, um segmento da Linguística. Segundo Barthes (2006), todo "sistema semiológico repassa-se de linguagem e pode significar sob a linguagem, mas nunca sem ela” (BARTHES, 2006, p. 12).

Sendo assim, Barthes (2006) insiste em algumas das categorias de Saussure (2006), inclusive a principal delas, a relação entre língua e fala, a fim de analisar sistemas de significação essencialmente imagéticos, como o da moda. É por meio dos mesmos princípios, ainda, que ele avalia a gastronomia, a indústria automobilística e o mobiliário burguês. Nesses exemplos mencionados, seu interesse se concentra no jogo entre um sistema ideal, ditado por interesses econômicos e publicitários, que no caso de Saussure, corresponderia à língua, e o uso comum, atribuído aos consumidores e identificado na vida corrente, que equivaleria à fala.

Em síntese, Barthes (2006) preconiza que, quando se trata de sistemas de significação, ainda que de predominância não verbal, torna-se necessário não perder de vista a perspectiva da linguagem que forma esses sistemas e, ao mesmo tempo, garante que eles mantenham os seus efeitos discursivos. Na mesma linha, o best-seller de Vilém Flusser (2011), Filosofia da Caixa Preta, de 1983, é precedido de um glossário, fazendo lembrar um pressuposto-chave do filósofo em suas análises sobre os meios produtores de imagem técnica: aparelhos são, no limite, extrapolaçóes concretas de textos científicos (FLUSSER, 2011, p. 
17, 29). Barthes (2006) e Flusser (2011) parecem defender, portanto, que a crítica do tempo presente, aparentemente dominado pelas imagens, demanda o esforço de perseguir e esmiuçar as suas organizaçóes de linguagem, já que estas revelam, quase sem exceção, uma sustentação de cunho linguístico.

Embora não seja o objeto de análise deste trabalho, seria interessante um estudo que refletisse sobre as fake news em seu caráter estrutural. Sabemos, por exemplo, que as fake news costumam acompanhar a estrutura dos textos jornalísticos, uma vez que estes, apesar de suas arbitrariedades, ainda se mantêm, convencionalmente, como um tipo discursivo ligado à expressão imparcial e objetiva do verdadeiro. Da mesma forma, caberia investigar, com base na premissa de Barthes (2006), a linguagem em que se articulam as fake news que se apresentam sob a forma de imagens (montagens, memes, vídeos etc.). Para além do seu conteúdo falso e artificioso, que é o aspecto mais evidente das fake news, o escrutínio da linguagem dessas produções informativas pode ser esclarecedor para a compreensão de sua disseminação em massa. Sem dúvida, a Semiótica, como campo de estudo, teria muito a contribuir nessa direção teórica.

Este é o empenho de Barthes (2001), em Mitologias, de 1957. Nas inúmeras e breves análises desenvolvidas ao longo da obra, que, segundo o próprio autor, seguiram a lógica da sua observação do cotidiano, ele expóe a diferença crucial entre os sistemas de significação e os sistemas fatuais e a forma recorrente com que sistemas semiológicos, isto é, construídos, são tomados como sistemas objetivos. Esta seria a principal característica do mito: a transformação da história em natureza, convertendo os produtos da história em tipos essenciais. Além disso, o amito faz com que a imagem provoque naturalmente o conceito, ou fazer com que o significante crie naturalmente o significado. $\mathrm{O}$ mito faria de toda intenção história um determinismo oriundo de um mundo estático e distante, alheio às forças de poder. Também faria da contingência um pretexto para a visão da eternidade.

Para o contexto deste trabalho, não seria despropositado pensar as fake news à luz das mitologias cotidianas analisadas por Barthes (2001). O mito, como as fake news, define-se por uma fala excessivamente justificada. Seu caráter impressivo deve ser imediatamente perceptível, dispensando a mediação da palavra crítica e interpretativa. Segundo Barthes (2001), o que se espera do 
mito é um efeito direto, e pouco importa se, em seguida, é desmontado, já que, presume-se, "a sua ação é mais forte do que as explicaçóes racionais que podem pouco depois desmenti-lo” (BARTHES, 2001, p. 151).

Os homens não manteriam com o mito, como não mantêm com as fake news, relações de verdade, mas de utilização. Para Barthes (2001), o mito é uma fala despolitizada, já que ignora a política em sentido profundo, como conjunto de relaçóes humanas em sua estrutura real, social e em seu poder de construção do mundo. A fala do mito pode até ser inicialmente política, mas termina por ser natural, diferentemente da fala revolucionária, que se deseja inicial e finalmente política, pois imagina como fim último de todo discurso uma mudança social efetiva. Nas palavras de Barthes (2001), o mito evacua o real:

O que o mundo fornece ao mito é um real histórico, definido, por mais longe que se recue no tempo, pela maneira como os homens o produziram ou utilizaram; e o que o mito restitui é uma imagem natural deste real. E, do mesmo modo que a ideologia burguesa se define pela deserção do nome burguês, o mito é constituído pela eliminação da qualidade histórica das coisas: nele, as coisas perdem a lembrança da sua produção. $\mathrm{O}$ mundo penetra na linguagem como uma relação dialética de atividades, de atos humanos: sai do mito como um quadro harmonioso de essências. Uma prestidigitação inverteu o real, esvaziou-o de história e encheu-o de natureza, retirou às coisas o seu sentido humano, de modo a fazê-las significar uma insignificância humana. A função do mito é evacuar o real: literalmente, o mito é um escoamento incessante, uma hemorragia, ou, se se prefere, uma evaporação; em suma, uma ausência sensível (BARTHES, 2001, p. 163).

Como foi postulado na introdução, o homem é um ser dotado de linguagem, isto é, somos seres simbólicos, o que reveste a realidade do que Lúcia Santaella (2007) chama de "crosta sígnica" (SANTAELLA, 2007, p. 11). A própria noção de vida, depois que cientistas forjaram o código genético, 
converteu-se em objeto de informação. Sendo assim, o mito seria uma fala que perdeu o contato com o mundo sensível, cuja narrativa exclui a contingência histórica e se cristaliza em monumentos naturais.

Se parece inegável que o processo de conferir sentido ao mundo demanda que o codifiquemos, em contrapartida, nunca se mostrou tão urgente desfazer as tentativas discursivas que se pretendem imediatamente compreensíveis, tais como as fake news, afinal, o mundo cada vez mais mediatizado em que vivemos (redes sociais, smartphones, câmeras fotográficas de alta resolução, drones etc.) alimenta, a todo instante, a utopia de uma vida imediata, transmitida e compartilhada ao vivo, em "tempo real".

A ação política passaria por fazer de toda fala um "ato de fala". Mikhail Bakhtin (2006) defende essa posição em Marxismo e Filosofia da Linguagem, publicado em 1929. Ele divide o processo de enunciação em tema e significação. O primeiro é concreto e implica o fenômeno histórico ao qual a enunciação está vinculada. O segundo é formado por elementos reiteráveis e idênticos e reduz-se à condição de um aparato técnico para a realização do tema. É evidente que, para Bahktin (2006), a significação representa um estágio inferior da capacidade linguística de significar. No entanto, menos do que ignorar o jogo com a linguagem, fundamental para que todo discurso possa fazer sentido, o filósofo prefere ressaltar que uma enunciação é considerada política apenas se estiver ligada a uma realidade concreta e não verbal.

Toda enunciação carrega, assim, um "acento apreciativo" ou "entoação expressiva”. Para Bakhtin (2006), o apreciativo é inseparável do significativo. Compreender, para o filósofo, é ter a capacidade de responder, já que a significação não está na palavra ou na alma do falante, mas na troca dialógica: "Compreender é opor à palavra do locutor uma contrapalavra" (BAKHTIN, 2006, p. 135). As fake news, nessa perspectiva, podem ser definidas como discursos significativos desprovidos de tema. As fake news formam um tipo de enunciação que não requer resposta, mas confiança.

Em 1970, com $A$ ordem do discurso, Michel Foucault retoma as teses nietzschianas para reafirmar que a verdade se estabelece discursivamente ${ }^{5}$. Em tempos

5 O ensaio "Sobre verdade e mentira no sentido extra-moral" é traduzido ao francês em 1969. 
de naturalização dos conceitos e de esvaziamento do sentido das palavras, Foucault (1999) solicita que nos voltemos para as operaçóes discursivas que tornam possíveis as nossas próprias falas, suspendendo, temporariamente, os seus conteúdos, já que as relações de poder, como também já previu Benjamin (1994), não são apenas repressivas, mas também produtivas: "Foi preparado um lugar que o honra mas o desarma" (FOUCAULT, 1999, p. 7). O discurso não traduziria as lutas sociais ou os sistemas de dominação, mas seria o objeto mesmo do enfrentamento.

Com as redes sociais, a clássica divisão entre poucos autores e muitos leitores se desfez. Todos podem produzir discurso, mas caberia, como salienta Foucault (1999), questionar se todos estão incumbidos do poder conferido por ele. Todos falam e todos publicam, mas o próprio aparelho, conforme prevê Flusser (2011), parece ser o destino dessas falas, como também o responsável pelo feedback. O desafio proposto por Foucault (1999) é o de recuperar o caráter de acontecimento do discurso.

No contexto brasileiro, a jornalista e escritora Eliane Brum, em consonância com a tese aqui defendida, levanta a hipótese de que a crise brasileira é, fundamentalmente, uma "crise da palavra". A tragédia brasileira, para Brum (2016), não é que as palavras sejam necessariamente censuradas, como no tempo da ditadura, mas que as palavras que se dizem já não dizem: "Esta crise não é apenas política e econômica. É uma crise de identidade - e é uma crise da palavra. São as palavras que nos arrancam da barbárie. Se as palavras não voltarem a encarnar, se as palavras não voltarem a dizer no Brasil, o passado não passará. E só nos restará pintar o rosto com sangue" (BRUM, 2016, s/p) .

O rosto pintado de sangue é o de Sheila da Silva, que, depois de buscar cenoura, batata e pão no supermercado, subiu o morro e encontrou o filho morto, coberto por um lençol, à porta de casa. Com o sangue do filho, ela pintou a face de vermelho: "O que se chama de realidade objetiva tornou-se uma vivência do inconcebível” (BRUM, 2017,

6 De modo semelhante, a filósofa Marie-José Mondzain (2009) fala em “imagens encarnadas" para se referir às imagens que ganham carne, mas não ganham corpo. Nesse sentido, as imagens encarnadas se contrapóem às imagens personificadas, típicas de regimes fascistas, já que concedem ao espectador uma ausência sensível que assegura o espaço da leitura crítica. Nas imagens encarnadas, não há fusão entre espectador e objeto ou pessoa figurada. Ver referência ao final. 
$\mathrm{s} / \mathrm{p})$. Como já se discutiu anteriormente, cumpre também investigar as fake news fora da dicotomia verdade e mentira, mas como autoverdade. Palavras que prescindem de qualquer materialidade. Significaçôes sem tema. Metáforas sem apelo estético. Palavras desencarnadas. Palavras-carta que não chegam a nenhum destino. A sugestão deste ensaio é pensar uma forma política e imaginativa de pensamento que faça do aspecto aparentemente náo objetivo da realidade uma oportunidade para retomar o contato com a materialidade sensível das coisas. Lá onde a política se faz. Lá onde palavras são efetivas.

\section{Referências}

BAKHTIN, Mikhail. Marxismo e Filosofia da Linguagem. Trad. Michel Lahud. 12 ed. São Paulo: Hucitec, 2006.

BARTHES, Roland. Mitologias. Trad. Rita Buongermino e Pedro de Souza. 11 ed. Rio de Janeiro: Bertrand Brasil, 2001.

. Elementos de Semiologia. Trad. Izidoro Blikstein. São Paulo: Cultrix, 2006.

BENJAMIN, Walter. Magia e técnica, arte e politica: ensaios sobre literatura e história da cultura. Trad. Sérgio Paulo Rouanet. São Paulo: Brasiliense, 1994.

BERNARDO, Gustavo; GULDIN, Rainer. O homem sem chão. A biografia de Vilém Flusser. São Paulo: Annablume, 2017.

BRUM, Eliane. O golpe e os golpeados. El país, https://brasil.elpais.com/ brasil/2016/06/20/opinion/1466431465 758346.html, 20/06/2016.

. O Brasil desassombrado pelas palavras-fantasmas. El país. https://brasil. elpais.com/brasil/2017/07/10/opinion/1499694080_981744.html, 10/07/2017. BUCK-MORSS, Susan. Estética e anestética. O 'ensaio sobre a obra de arte' de Walter Benjamin reconsiderado. UFSC: Outra Travessia. UFSC: 11-41, Florianópolis, 1996.

DERRIDA, Jacques. Anne Dufourmantelle convida Jaques Derrida a falar Da hospitalidade/Jacques Derrida [Entrevistado]. Trad. Antônio Romane. São Paulo: Escuta, 2003.

FLUSSER, Vilém. Lingua e Realidade. São Paulo: Annablume, 2007. 
. Bodenlos: uma autobiografia filosófica. São Paulo: Annablume, 2007. . Filosofia da Caixa Preta: ensaios para uma futura filosofia da fotografia. São Paulo: Annablume, 2011.

FOUCAULT, Michel. A ordem do discurso. Trad. Laura Fraga Sampaio. 21 ed. São Paulo: Loyola, 1999.

HJELMSLEV, Louis. Prolegômenos a uma teoria da linguagem. São Paulo: Perspectiva, 2006.

MONDZAIN, Marie-José. A imagem pode matar? Trad. Susana Mouzinho. Lisboa: Nova Veja, 2009.

NIETZSCHE, Friedrich. Sobre Verdade e Mentira no Sentido Extra-moral. Trad. Rubens Torres Filho. Antologia de Textos Filosóficos: 530-541, Curitiba, 2009.

SANTAELLA, Lúcia. O que é Semiótica. São Paulo: Brasiliense, 2007.

SAUSSURE, Ferdinand de. Curso de Linguistica Geral. Trad. Antônio Chelini, José Paulo Paes e Izidoro Blikstein. 11 ed. São Paulo: Cultrix, 2006.

SLOTERDIJK, Peter. O desprezo das massas: ensaio sobre lutas culturais na sociedade moderna. Trad. Claudia Cavalcanti. São Paulo: Estação Liberdade, 2016.

\title{
FAKE NEWS IN AN EXTRA-MORAL SENSE, OR ON THE MATERIAL REALITY OF THE WORDS
}

\begin{abstract}
:
The present essay postulates that reality structures itself linguistically. Bases on that, the paper reflects on a political and imaginative way of thinking that makes of the seemingly non-objective aspect of reality an opportunity to resume contact with the sensible materiality of things and with the effectiveness of words. This implies reflecting on fake news beyond the dichotomy truth and lies.
\end{abstract}

KEYWORDS: reality; language; fake news. 
